\title{
Norwegian Computer Technology: Founding a New Industry
}

\author{
Yngvar Lundh \\ Østre vei 26, 3152 Tolvsrød, Norway \\ yngvar@ifi.uio.no
}

\begin{abstract}
Norway had a successful computer industry. A small group of young research engineers who saw a new era and started "from scratch" founded it. They were able to harness and exploit the rapid development by a basic technical research project.
\end{abstract}

Keywords: Computer, display, hardware, light pen, magnetic core, memory, reliability, transistor.

\section{Introduction}

In the early 1960s, a small group of enthusiastic young engineers developed some basic computer technologies. They built their own basic knowledge and created digital circuits, devices and systems, based on technical literature and academic visits to the United States. They made no contact with similar projects. In the late 1960s, members of the group initiated and had the quintessential knowledge in Norsk Data, Informasjonskontroll (ND) and a new division of Kongsberg Våpenfabrikk. These were successful industrial enterprises; ND became large indeed. This is my account on the way the fostering of the technology and the enthusiasm occurred.

\section{Study}

As a student of electrical engineering at the Norwegian Technical University - NTH I was looking forward to my final thesis term in 1956. I had come across a book about the "Mark1"-effort at Harvard and other "electronic brains." I asked docent Jens Balchen whether he might be interested in giving me a topic in that area. Balchen had made an impression by his open mind and his singlehanded development of the analog computer "Diana." I had invited him to tell us about it in our radio club, where I spent my spare time with fellow students rebuilding the ham radio station that had been nonexistent since the war.

After a while I was told that nobody at NTH had the knowledge to suggest a topic for study of electronic brains. However, Balchen's friend research engineer Karl Holberg of the Norwegian Defense Research Establishment - NDRE - at Kjeller, proposed a topic. They invited me to do my thesis work there and to investigate an idea, proposed in a journal. That method could multiply, add and divide numbers 
represented by frequencies of pulse trains. I called it "Siffer frekvens systemet" [1]. Programmable computers were very costly indeed, and cheaper means of computing might be useful in automatic control, signal processing etc. I subsequently worked for NDRE until 1984.

\section{Solid State Devices?}

In that investigation, I built a set of modules to be interconnected and used for experiments. The modules were binary dividing chains and counters, all implemented by vacuum tubes. During that term and for the next couple of years I did much reading about circuits and devices that might be usable for digital systems. I became concerned by reports of the limited lifetime of vacuum tubes and the ensuing unreliability of systems.

One fellow student's diploma work had been to investigate if a small, much heralded, component, called transistor, might be useful for hearing aids. His professor brought him a sample from an American laboratory. The student had sadly concluded: No. However, transistor radios came on the market. Solid-state components became a promising possibility for replacing tubes in the future. Many practical factors made that choice a long-term one. Between various assignments at NDRE after my graduation, I was able to do a fair amount of reading about solid-state devices. I was especially intrigued by magnetic devices also. Could we possibly use them for implementing logic functions?

I tried to obtain answers to some more or less wild questions and ideas by the assistance of graduate students. Both professors Balchen and Westin at NTH and Tangen at the University of Oslo (UiO) accepted some of my ideas for topics of thesis work for their students, some of them quite brilliant. I served as their advisor and they did their studies as members of our research group at Kjeller. All of us gradually became captivated by the possibilities we saw in digital technology.

\section{From the United States}

I saw reports about "mathematics machines" such as BESK, DASK and NUSSE, but - rightly or wrongly - I decided to seek solutions that were more promising. I was warned by prominent research committee members that such machines, now in development elsewhere, would have adequate capacity for the foreseeable mathematics market, hence precluding need for Norwegian effort in that area. I decided to spend some time in the United States, where computer technology now apparently was actively being developed and exploited. From august 1958 through 1959 I worked at MIT in the famous Servomechanisms Laboratory, first as "guest" living on a fellowship awarded by the Norwegian research council, later employed by MIT as manager of a project to develop a "pulsed analog" computer. Besides auditing classes in signal theory and automata, I spent much of my time in the special lab established around a computer called TX-0.

As a computer, the TX-0 was somewhat odd as it was built for a special purpose. It was, however, a truly programmable computer; it had a good directly driven CRT 
display, and - most important - its circuits were all transistorized. Moreover, it was available! I could sign up for time and then use it solely for my own purposes. That was rather different from MIT's main computer center. It featured a monstrous IBMmachine occupying its special wing of the building, with users delivering stacks of punched cards through a window and receiving thick printouts.

Part of the time I went around the back of the "little" TX-0, studying circuit details using an oscilloscope. Additionally, I learnt how to program it, meticulously punching machine code on to paper tape. My proud top success was when the Boston Globe published a story about my program that enabled people to play Tic-tac-toe with the computer, using a "light-pen" that could paint on its display screen. Well, machine code - someone developed a program to translate "mnemonic" three-letter codes, a precursor to assembly code, making the bits of the machine code much easier to remember.

All of this made me entertain ideas that we must develop such machines back home, only much better ones. Karl Holberg, who stopped by the lab on one of his visits in the US, supported the idea heartily. I was even more dedicated after visiting a conference in Boston, where Kenneth Olsen displayed a "programmed data processor" - PDP-1 - a computer to become quite important later, the incipient "minicomputer." Olsen, who told me his parents had come from Fredrikstad, Norway, had started Digital Equipment Corporation after finishing his central role at designing the TX-0 and much else at MIT's Lincoln Lab. We had DEC's logic modules at the TX-0 lab.

\section{Building a Development Team}

Back at Kjeller in 1960, I was first disappointed to learn that finding resources for developing a computer would take time. However, something else came up. Someone had theorized on ideas that digital techniques could possibly enhance signals buried in noise. This idea could develop into an important project; someone would be happy to finance a digital signal processor if one could build it. I was lucky to be able to propose one. Money became available and there was a need to see results soon. An intense development program began. It resulted in a machine consisting of four large cabinets full of transistorized digital circuits. It worked as planned, processing signals. The only thing it could do was that process, but it did perform it in real time, which was beyond what known programmable computers could do at the time.

To deliver that machine quickly, we had to employ some new engineers. We soon became a group of young engineers. Two of them, fresh after completing their thesis work in digital electronics were Lars Monrad Krohn and Per Bjørge. A period of intensive development began. We viewed some issues very seriously and they were probably decisive for our success.

\section{Transistors!}

Without doubt, transistors would be the active components! Some were now commercially available, but critical characteristics varied greatly. We needed hundreds 
of transistors. Circuits were carefully designed using classification of each component type to make the circuit perform to specifications even in the most unfavorable combination of values. We called it a worst-case design. We designed and implemented a few building blocks on printed circuit boards. Typical modules were a "flip flop" and an "inverter." We could implement any digital logic using the modules. Great care ensured standardized compatibility; each module carefully documented with practical rules for interconnection.

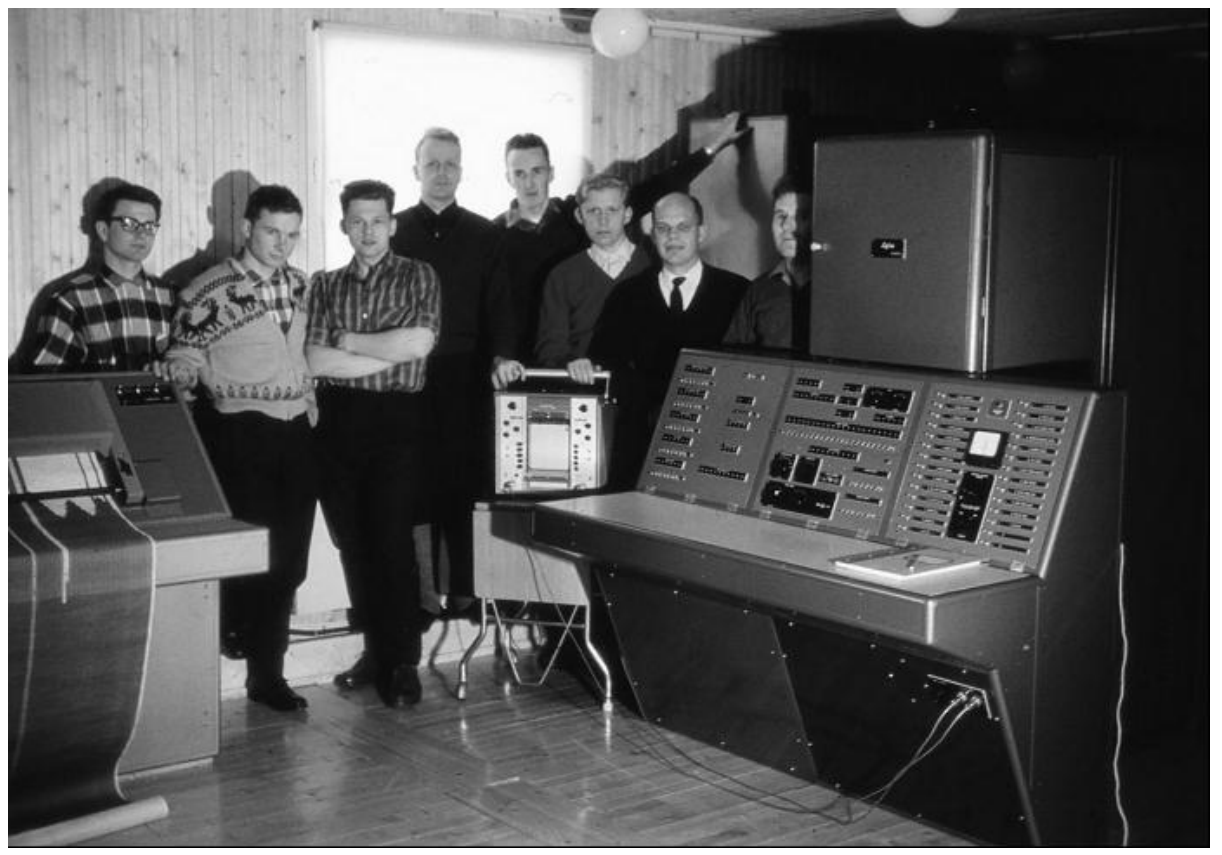

Fig. 1. "Siffergruppen" and the "Lydia" digital signal processor. From left: Per BuggeAsperheim, Svein Strøm, Per Klevan, Lars Monrad-Krohn, Per Bjørge, Asbjørn Horn, Olav Landsverk, Yngvar Lundh (Ove Raffelsen not present).

Extensive work went into the mechanical design of racks, "drawers," guides for cards, and interconnection plugs. It is fair to say that Monrad-Krohn was an essential force in that design process. He spared no effort to meet requirements to ensure reliable performance and he inspired the entire group with his overwhelming energy and his uncompromising determination. Bjørge was an eminent designer of circuits meeting worst-case requirements. A pioneering spirit was growing. "Printed circuits" was something we had heard of, but never seen. Numerous considerations aiming for reliability went into combined effort of the little team of engineers fresh out of university (Fig. 1). The complete machine, named "Lydia," was put to work in March 1962.

Our development must have made impression. It now became possible to think of a general purpose, programmable computer, a dream not forgotten since my return from MIT. Holberg, now leader of a large project, foresaw the need for a machine to handle experiment data and assigned Siffergruppen, now an honorable name, to build one. 


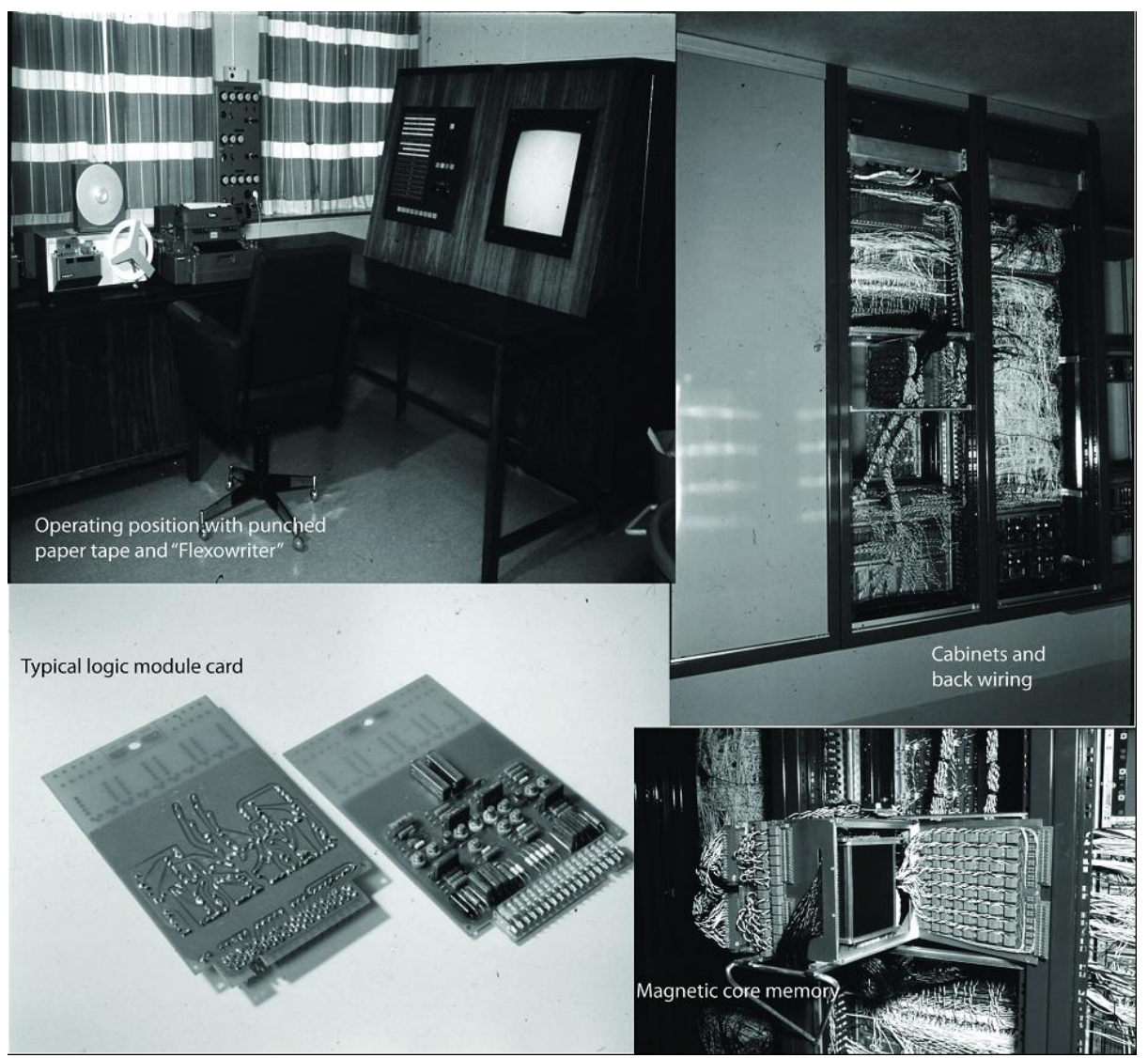

Fig. 2. SAM

The goal of the new project "build a computer as fast as possible" was unusually vague. However, reflecting on our ambitious attitudes prevailing at that time, "mathematics machines" were exotic news items. The project was named SAM, for simulator of automatic machinery. The same team, augmented by a couple of new candidates who had just completed their theses and became associated members of the group developed it. SAM, a fast programmable computer for that time, was developed and built. It was used for experiments at NDRE until 1973. Since then, it has been an exhibit at the Technical Museum in Oslo.

\section{Component Prices}

Transistors then on the market were much better than those we had used in Lydia, but way too expensive. We estimated need for more than one thousand. However, I had noted a tendency of extreme price falls happening to new components that became winners in the market. Hence, we carefully studied ambitious market launches of very 
fast transistors. The advent of the planar process had made possible competing production of equivalent transistors. Semiconductor companies now recognized that "second sourcing" of components was now a necessity in the market rather than something to avoid. These were two factors of unquestionable importance for the use of semiconductors in computer circuits from the early 1960s. Gambling on a dramatic drop in prices, I bought samples of some promising transistors. Prices were exorbitant, so I could only buy three samples for testing and circuit design. We were lucky to pick winners in that race. A few months later when we needed a great number of those transistors, prices had fallen even more than expected. The speed of our new logic circuits had increased several hundred times over those of Lydia. We retained the mechanical standards of cards and interconnection.

In a process over several months, the overall design of the computer was defined in detail. It ended up with features that turned out to point ahead while some were dead ends. I had kept my belief in magnetic components. For the main computer memory, I meant to see a future for thoroidal magnetic cores. Reportedly, they were promising and some companies began to offer them commercially. A study-process made us end up buying from Philips a complete matrix of $64 \times 64 \times 25$ bits. Olav Landsverk was responsible for careful design of driving and sensing circuits, including error detection logic. That became the main memory of SAM and it worked fine. I became intrigued by a possible design of an associative memory, using multi-aperture magnetic cores, and soon, we started the circuit design for it. SAM's instruction set contained commands for the associative functions. I found out later in the design work that some clever commands using the ordinary memory would outperform the associative ones. So, we abandoned the idea of associative memory - fortunately. The concept of index memory emerged during those months. We purchased some "very fast" experimental memory modules using thin magnetic film deposited on glass rods for it. Suitable drive circuits were designed, and they worked. I believe the experience of that effort was more valuable than the resulting improvement of computing power. We pursued a number of ideas during some quite creative and busy months.

From my experience with the TX-0, I was convinced of the value of a display screen for which a pen light made interactive. We did not see computer screens for many years to come, of course. I had found a rather special device, called the Charactron Shaped Beam Tube. It projected character symbols on the screen by a form of electron optics. Purpose was to make the display faster and more responsive in interaction. The Charactron was large, it required very special drive circuits indeed, and was expensive. Moreover, it was sensitive of the earth's magnetic field and had to be completely shielded in a "mu-metal" casing. A new member in our group, Knut Korsvold, made the entire design. He met a design challenge of unusual complexity, and succeeded. The display worked reliably. A little device called light pen also comprised some tricky problems. Bugge Asperheim developed a working light pen connected to the display.

The complete machine was developed, built and was working by mid-1964. Later some further additions were made to it. In August 1964, we presented several papers about SAM the NordSAM conference in Stockholm [2]. 


\section{Confirming Experience}

During the same period, when SAM was under development, we received another challenge. The telecom administrations of Sweden, Denmark and Norway had decided they wanted to begin experiments with satellite communications. They needed a system to steer a large antenna for experiments. Ground stations for that purpose had been built in some other countries. They were computer controlled, but that made them too expensive for the Scandinavians' budgets. I was asked for a suggestion, and luckily was able to come up with a proposal that the telesatellite committee accepted. Using the well-proven Lydia type modules, we built a special purpose machine that could predict the pointing coordinates of the antenna. Jan Garwick, astronomer and head of NDRE's mathematics section, helped me with the mathematics of approximation of the predicted ephemeris data of satellite orbits, by second-degree polynomials. The machine used the principles of "Siffer frekvens systemet" that I had investigated in my thesis.

The electronics filled four large cabinets of card modules. The machine, "Rasmus," was installed July 1964 at the antenna station at Råö in Bohuslän. Einar Evensen of NDRE developed the powerful servo system that converted the analog output signals from Rasmus into physical pointing angles of the large antenna. The 25 -meter disk was a radio telescope built for astronomy. It became available to the telesatellite committee for telecommunication experiments, and now enabled the telecom administrations to demonstrate, for the first time, direct transmission of TVsignals from California to Scandinavia. Again, a special purpose computer had become the solution in real time control.

\section{Software}

Various bits and their combinations defined the instruction set of SAM. Commands had three letter "mnemonic" names. We recognized the need for an assembly program. Martin Vånar doing his thesis work in our group was inspired by Jan Garwick's ideas of program structures. Vånar wrote a great assembler called Samba. (Garwick's group became a source of some powerful software innovations, but that was later). Monrad-Krohn now came back from a sabbatical year at MIT, full of new ideas and enthusiasm, especially about programming. Thinking that Samba was too complicated, he quickly wrote an assembly program called Asem. It became the dominant software tool for programming SAM. The ideas of operating system programs did not really occur to us until a little later.

\section{Industrialization}

We learned many lessons during these years. First, we began to understand the workings of computers. We saw that it was possible to make them. We learned how to use them, how to do things, and what not to do. From the end of 1964, Monrad-Krohn headed Siffergruppen, when I had to leave for another assignment. The group went on growing and developed newer and better machines. SAM-2 was developed for some 
real time applications. Growing knowledge was valuable. Integrated circuits had now become a reality. Features of SAM indicated what was good, and what was less valuable. We built experience.

Some new young engineers and students joined from time to time. Rolf Skår was one of them. As a period of industrialization began, several members of the group left, to join the new organizations. In 1967, time had come to go out and industrialize this know-how. Three members of Siffergruppen, Lars Monrad-Krohn, Per Bjørge, and Rolf Skår, took the initiative to found a new company, later called Norsk Data - ND. Martin Vånar founded a consulting company - Industrikontroll. Kongsberg Våpenfabrikk - KV - employed Olav Landsverk and others. Several books were written about that period [3].

A computer for field artillery was the next great opportunity that came up. It ultimately became a great success for KV. In a short time, commercial ideas and marketing realities had pervaded the group. Technical arguments between the two emerging industrialists ND and KV appeared belligerent. The atmosphere smelled hostile. Probably the competition was a useful stimulus, though, viewed in retrospect.

Both launched their series of "minicomputers" - in competition. As for myself, I wished them success, but after careful consideration, I decided to stay with NDRE and attend to some other opportunities. Each of the companies achieved significant success. ND became large and for a while, it was the largest corporation in Norway, measured by stock value [4].

\section{Trust and Success}

Our success was partly due to the "state of the art" in that period. We were able to make early use of some unique devices as they became available, hence getting a good start on the international scene. Most important was the rapid development of semiconductor components and circuits. Our results were ready for commercial exploit when minicomputers were making computing affordable for many new applications. There was a large and rapidly growing market.

Even with that, the success had not happened, were it not for the ability of those young engineers. They designed intricate computer electronics with enthusiasm and certain knowledge. It could be done, and it should be! Some of the design details of those early experimental circuits were quite difficult ones. Resources were small, creativity was great, previous experience was nil. We were reading about many types of difficulty leading into trouble elsewhere. That gave us respect for potential dangers. We were thus motivated for careful design, trying to think of everything that could possibly go wrong. Specifications, limits and tolerances became household words. Throughout our little organization, everyone was conscious of the great potential of this wonderful new digital technology. We had promised that we could do it. We all thought that it was always up to us, only to ourselves, to succeed.

A significant reason for the success was trust. Karl Holberg gave us the permission to go ahead and develop SAM. It can best be called basic technical research. He shared my vision that digital techniques were to become important. He invented a possible application in a quite different large project, set aside a sum of money and assigned Siffergruppen to the task. In his own joking language, he said he stole the 
resources. Had we not succeeded in demonstrating unique performance and promising technology, that joke might have turned rather sour. He never told us what to do, but trusted us to do what we had promised. The enthusiasm and responsibility felt by every member were most valuable results of that trust. Young people were stimulated to take responsibility and do what they were good at doing. Self-confidence carried over into the industry it spawned, and continued to grow.

\section{References}

1. Lundh, Y.: Digital Techniques for Small Computations. J. of the Brit. I.R.E. 19, 37-44 (1959)

2. Holberg, K., Lundh, Y., Bjørge, P., Landsverk, O., Raffelsen, O., Korsvold, K., BuggeAsperheim, P.: Regnemaskinen SAM. Elektroteknisk Tidsskrift special issue (August 1965)

3. Wicken, O.: Norsk datahistorie. Prizewinning essay, Ingeniørforlaget/Teknisk Ukeblad (1989)

4. Heradstveit, P.Ø.: Eventyret Norsk Data: En bit av fremtiden. J.M. Stenersens forlag (1985) 